\title{
Flop to Flip: Integrating Technology and Team-Based Learning to Improve Student Engagement
}

\author{
Diana A. Veneri \\ Sacred Heart University, venerid5@sacredheart.edu \\ Elizabeth M. Mongillo \\ Quinnipiac University, Elizabeth.Mongillo@quinnipiac.edu
}

Follow this and additional works at: https://nsuworks.nova.edu/ijahsp

Part of the Adult and Continuing Education Commons, Educational Technology Commons, Health and Physical Education Commons, Medicine and Health Sciences Commons, and the Scholarship of Teaching and Learning Commons

\section{Recommended Citation}

Veneri DA, Mongillo EM. Flop to Flip: Integrating Technology and Team-Based Learning to Improve Student Engagement. The Internet Journal of Allied Health Sciences and Practice. 2021 Jan 01;19(2), Article 10.

This Concept Piece is brought to you for free and open access by the College of Health Care Sciences at NSUWorks. It has been accepted for inclusion in Internet Journal of Allied Health Sciences and Practice by an authorized editor of NSUWorks. For more information, please contact nsuworks@nova.edu. 


\title{
Flop to Flip: Integrating Technology and Team-Based Learning to Improve Student Engagement
}

\begin{abstract}
Purpose: The first attempt to develop and instruct a new course in evidence-based practice in a physical therapy curriculum proved problematic. The purpose of this paper is to describe the method of revising this traditionally taught course using a combination of flipping the classroom, team-based learning, and technology. Methods: Working with an Instructional Design Specialist, a weekly online preparatory module was created for each content topic using a variety of multimedia learning provisions including micro learning videos (PowerPoint with voiceover), transcript of the PowerPoint, a list of vocabulary words, reading, Quizlet, Flipgrids and Concept Checks. Each week's module was introduced with a listing of objectives, goals, time to complete tasks and a description of the in-class activities. Class began with a weekly 10-question vocabulary quiz to hold students accountable for their preparation. A short summary lecture followed. Students were then given an in-class assignment to complete either in pairs or small groups. Discussion of the assignment completed the session. Most of the assignments were submitted electronically prior to discussion for grading purposes. Several also utilized a team-based learning format. Pairs of students complete an assignment; students then convene with their group and discuss and complete the same assignment. This process facilitates a more active learning environment. Result: Students were consistently prepared for class as evidenced by their quiz performance. Informal assessment of the online preparatory modules was performed using a "One-Minute Paper" assessment. Students reported that the PowerPoint with voiceover, Quizlet, Concept Checks, and the weekly list of vocabulary terms were most helpful, whereas Flipgrids and reading were not helpful. In-class activities were interactive and facilitated deeper conversations about the content. Conclusion and Recommendations: The outcomes provided reflect student perception solely, which may have been biased by the instructor's presence in the course. Formal assessment of changes was not possible using student performance as a measure because the course had dramatically changed from year one to year two. A more formal, scientific assessment is recommended to determine if and how course changes affected student performance.
\end{abstract}

\section{Author Bio(s)}

Diana Veneri, EdD, PT, RYT is an Associate Professor in the Department of Physical Therapy and Human Movement Sciences at Sacred Heart University.

Elizabeth Mongillo has a MA in Instructional Design and is an Associate Director of Finance at Quinnipiac University. 


\title{
IIJAHSP
}

\section{The Internet Journal of Allied Health Sciences and Practice}

Dedicated to allied health professional practice and education

Vol. 19 No. 2 ISSN 1540-580X

\section{Flop to Flip: Integrating Technology and Team-Based Learning to Improve Student Engagement}

\author{
Diana A. Veneri ${ }^{1}$ \\ Elizabeth MN. Mongillo²
}

1. Sacred Heart University

2. Quinnipiac University

United States

\begin{abstract}
Purpose: The first attempt to develop and instruct a new course in evidence-based practice in a physical therapy curriculum proved problematic. The purpose of this paper is to describe the method of revising this traditionally taught course using a combination of flipping the classroom, team-based learning, and technology. Methods: Working with an Instructional Design Specialist, a weekly online preparatory module was created for each content topic using a variety of multimedia learning provisions including micro learning videos (PowerPoint with voiceover), transcript of the PowerPoint, a list of vocabulary words, reading, Quizlet, Flipgrids and Concept Checks. Each week's module was introduced with a listing of objectives, goals, time to complete tasks and a description of the in-class activities. Class began with a weekly 10-question vocabulary quiz to hold students accountable for their preparation. A short summary lecture followed. Students were then given an in-class assignment to complete either in pairs or small groups. Discussion of the assignment completed the session. Most of the assignments were submitted electronically prior to discussion for grading purposes. Several also utilized a team-based learning format. Pairs of students complete an assignment; students then convene with their group and discuss and complete the same assignment. This process facilitates a more active learning environment. Result: Students were consistently prepared for class as evidenced by their quiz performance. Informal assessment of the online preparatory modules was performed using a "One-Minute Paper" assessment. Students reported that the PowerPoint with voiceover, Quizlet, Concept Checks, and the weekly list of vocabulary terms were most helpful, whereas Flipgrids and reading were not helpful. In-class activities were interactive and facilitated deeper conversations about the content. Conclusion and Recommendations: The outcomes provided reflect student perception solely, which may have been biased by the instructor's presence in the course. Formal assessment of changes was not possible using student performance as a measure because the course had dramatically changed from year one to year two. A more formal, scientific assessment is recommended to determine if and how course changes affected student performance.
\end{abstract}

Keywords: evidence-based practice, problem-based learning, team-based learning, adult learning, technology 


\section{PURPOSE}

This project took place at a small, private university in New England with 9200 annual students, 3000 of whom are graduate level. A typical cohort in the Doctor of Physical Therapy (PT) Program is comprised of 70 graduate students. The didactic curriculum is completed across five semesters in 24 months followed by the majority of the clinical education curriculum. According to the Commission on Accreditation in Physical Therapy Education's Aggregate Program Data: 2016-2017 Physical Therapy Education Program Fact Sheets, the majority of programs (75\% of 200$)$ are classified as hybrids, a combination of two or more models. Models are traditional $(10.2 \%)$, systems-based $(8.5 \%)$, modified problem-based $(3.5 \%)$, guide-based $(0.4 \%)$, case-based $(0 \%)$, problem-based $\left(1.7 \%\right.$ ) and lifespan $(0.04 \%) .{ }^{1}$ The curriculum of this project's PT Program is a hybrid, a combination of a modified problem-based learning and a case-based model. Barrow and Tamblyn (1980) define problem-based learning (PBL) as "the learning that results from the process of working toward the understanding or resolution of a problem."2(p.13) The problem presented in PBL is not simply one requiring the application of previous content-knowledge; rather the problem demands that students acquire new knowledge to address the problem through reasoning and learning skills. There are essentially four commonly used models of problem-based learning: completely integrated, transitional, modified, and single course.,4 By definition, a modified PBL curriculum uses case-based tutorials from the first semester of study to integrate content across concurrent basic science, clinical science, and professional development courses. ${ }^{5}$ The problem-based learning model has successfully been utilized in PT curriculi. $6-8$ The purpose of this project is to describe the process used to revise a traditionally-taught course to a hybrid curriculum to meet the needs of adult learners and enhance overall student engagement.

\section{BACKGROUND}

\section{The Modified PBL Curricular Design}

Each semester is organized chronologically by primary content topic: orthopedics of the extremities, neurology, cardiopulmonary/medically complex, orthopedic of the spine and business. The three foundational courses of Structure and Function, Examination and Documentation, Evaluation and Intervention were developed based on the Guide to Physical Therapist Practice and taught via PBL. By definition, a case-based curriculum utilizes cases as underlying themes throughout the curriculum. ${ }^{8}$ Course content aligns with the 26 tutorial cases each semester. ${ }^{5}$ Each case includes a different primary diagnoses and corresponding patient scenario. Student tutorial group ( $n=6$ or 7 students per group, 10-11 groups) assignments differ each semester. Cases are divided by topic: anatomy, pathology and prognosis, composition evaluation/medical intervention, PT evaluation, PT intervention, and social/other. Each group member investigates his/her assigned topic and reports back to/teach the group. To ensure that students cover each case to the expected depth and breadth, each tutorial group is facilitated by a faculty tutorial leader. Each case concludes with a faculty-facilitated large group discussion with the entire student cohort. Weekly lab activities coordinate with PT examination, evaluation, diagnosis, prognosis, and intervention related to the cases.

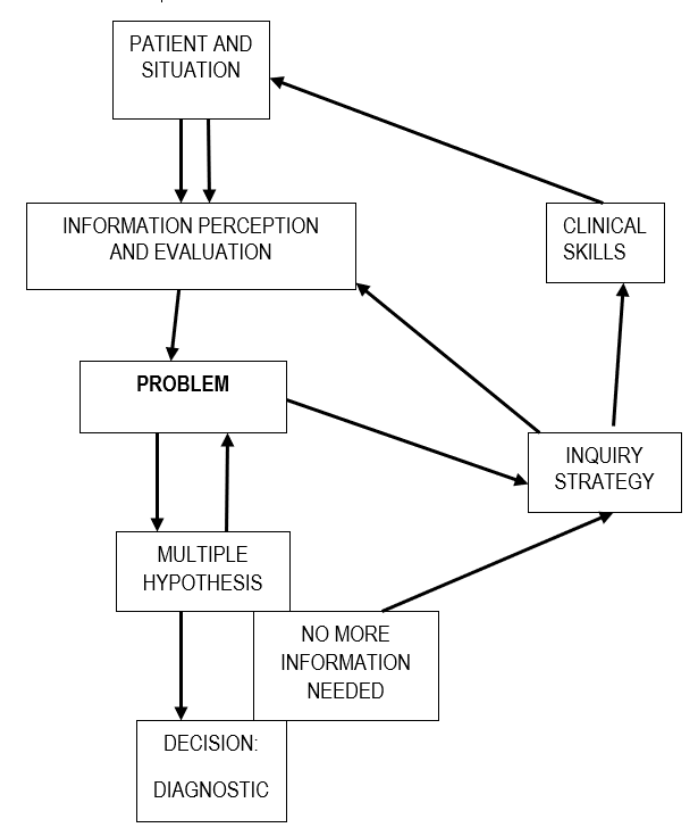

Figure 1: Problem-based learning model: When the clinician has obtained sufficient information to establish his hypothesis or probable hypotheses, he closes the process and makes a diagnostic and management decision. ${ }^{2}$ 


\section{Evidence-Based Practice Curriculum}

Historically, the didactic portion of the evidence-based practice (EBP) curriculum was embedded in the Examination and Documentation course of the second semester. Students disliked the reality that poor performance with the EBP content detracted from their grade in this core course. Faculty decided to evolve the EBP content into a separate course. The program curriculum was revised to accommodate the additional two credit course without changing the total number of credits needed for program completion.

The ultimate goal of PT 642 Foundations in Evidence Based Physical Therapy is for students to be competent evidence-based practitioners; that is, students should be able to ask a searchable question, search the literature, appraise the literature, integrate literature into clinical practice, and improve the quality of patient treatment. ${ }^{9}$ Course development incorporated content guidelines provided by the EBP Special Interest Group of the Research Section of the American Physical Therapy Association. ${ }^{10}$

\section{Statement of the Problem}

Year one, the course was developed and traditionally taught with face-to-face lecture as the primary means of content dissemination. There were weekly quizzes to lessen the intellectual burden of large exams. As with many new courses, problems emerged. Based on course evaluations, it was clear that students perceived PT 642 as additional to the core curriculum. Because the EBP content did not directly correlate with the semester's tutorial cases, students did not value its importance. Students admitted to their struggles and difficulties keeping up with the advanced content. Because the face-to-face time was a lecture format, students perceived class as largely an "information dump" and their primary information source. As a result, students felt that they lacked significant interaction with the content itself. They did not perceive themselves in control of their learning and as the degree of difficulty increased, a learning gap emerged. The student's disparity between what they actually learned and what they were expected to learn by the end of the course proved inequitable. Student quiz performance indicated a lack of understanding of basic terminology and knowledge which ultimately interfered with student attainment of the larger scope, content, course goals and outcomes. Because EBP is a critical component within the didactic and clinical portions of the doctoral program, a new instructional strategy and approach was needed to remediate the disparity. The purpose of this paper is to describe the process used to revise a traditionally taught course using a flipped model and technology.

\section{THEORETICAL FRAMEWORKS USED TO GUIDE THE REVISION OF PT 642 Flipping the Classroom}

One of the teaching and learning models considered was flipping the classroom. The traditional lecture format of teaching in higher education has been criticized of late as a passive methodology. A call to transform teaching formats to student-centered learning environments emerged as early as the 1960 's. ${ }^{14} \mathrm{~A}$ flipped classroom is one that essentially inverts what is traditionally done in class with what is done outside of class. ${ }^{15}$ Students learn content prior to class and class time is used for "homework" activities, creating a more active learning environment. Support for the flipped classroom model in higher education includes allowing students to learn at their own pace, take more responsibility for their learning, it encourages active engagement with lecture material, frees up class time for more effective learning activities and faculty members have more interaction opportunities with their students. Figuratively speaking, the sage on the stage becomes the guide on the side with this teaching methodology. ${ }^{15}$

Nouri's et al. study examined 240 higher education students' perceptions of a flipped classroom in research methods. The questionnaire results revealed that a large majority of the students had a positive attitude towards flipped classroom, the use of video and Moodle (a Learning Management System), and that a positive attitude towards a flipped classroom was strongly correlated to perceptions of increased motivation, engagement, increased learning, and effective learning. Low achievers significantly reported more positively as compared to high achievers with regards to attitudes towards the use of video as a learning tool, perceived increased learning, and perceived more effective learning. Lack of a control group was a study limitation. ${ }^{16}$ Emerging support has demonstrated that student performance on written examinations is no different between traditional and flipped classroom teaching methods. ${ }^{17,18}$ In at least one study, student performance was superior in the flipped classroom compared to the traditional classroom. ${ }^{19}$ Flipped classrooms have appealing qualities for both large and diverse classrooms whose course design reflects a strong link between theory and practice. ${ }^{20,21} \mathrm{~A}$ study of a musculoskeletal disorder course found that student performance of those taught using a flipped format was superior to student performance of those taught traditionally. ${ }^{22}$ However, the flipped classroom in PT education currently lacks sufficient research support. ${ }^{16}$

\section{Team-Based Learning}

When considering the face-to-face interaction during class time, another teaching methodology considered is an extension of PBL and is referred to as Team Based Learning (TBL). It is characterized as a four-step process that facilitates student learning and participation before and during class. The four TBL stages are 1) student preparation, 2) readiness assurance, 3) application, and 
4) peer assessment. ${ }^{23}$ The first stage of TBL is similar to flipping the classroom, as students are required to read or watch a short online lecture prior to class. The readiness assurance process starts as students take a multiple-choice test in class-the individual readiness assurance test (iRAT). Next, the multiple-choice test is repeated by teams of students (tRAT) applying the immediatefeedback assessment technique (IFAT). The teams must agree on their answers and are given immediate feedback. This stage is followed by a procedure in which the teams are set to work on specific cases, their task being to apply the knowledge and information they have obtained during the whole process. All teams are asked to work on the same significant cases and asked to provide specific answers simultaneously. ${ }^{23}$

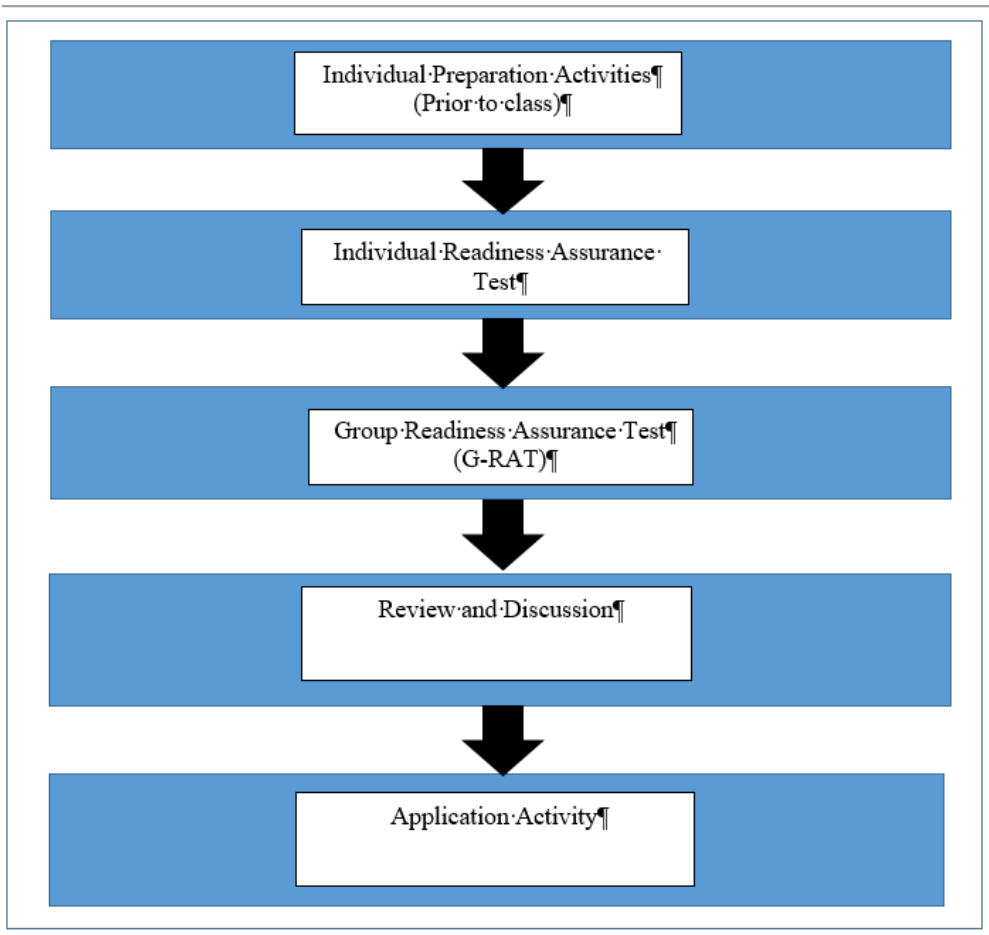

Figure 2. Team-based Learning Model

Jeno investigated the effects of TBL on motivation and learning in a quasi-experimental study. The study utilized a selfdetermination theory perspective to investigate the motivational effects of implementing TBL in a physiotherapy course. Researchers used a one-group pretest-posttest design. The results show that the students' intrinsic motivation, identified regulation, perceived competence, and perceived autonomy support going from lectures to TBL. Student engagement and perceived learning also significantly increased. Path analysis shows that increases in intrinsic motivation, perceived competence, and external regulation positively predict increases in engagement, which in turn predict increases in perceived learning. Another possible benefit of TBL is students' perception of faculty as supporters of autonomy, a hallmark of PT professional development. ${ }^{24}$ Macauley and Dirkes found that PT students had favorable responses to TBL preference in a diagnostic screening course; Livingston had similar results in a gross anatomy course. ${ }^{25,26} \mathrm{TBL}$ in PT literature generally reflects results based on student perspective and not actual performance. ${ }^{25,26}$

\section{Adult Learners}

The learner persona of a typical student cohort at the university can be characterized as a combination of non-skilled and skilled novices, where skilled refers to having hands-on healthcare experience and novice refers to having knowledge of PT. Some students have acquired hands-on skill working as clinic aides, while others only have observational experiences. This same characterization can be applied to EBP; the skill pertaining to prior knowledge of research methods is mixed. Some students have had the interest and opportunity to conduct a faculty-mentored research project as undergraduates, while others have not. Both types of learners are described as intrinsically motivated, with the non-skilled learner acutely aware of his/her inexperience. Both possess a variety of educational and technology capabilities. Educational strategies can be designed to facilitate motivation for adult learners. Many students find themselves ill-prepared for graduate school as many did not find it necessary to develop study strategies as undergraduates. Compounded with PBL as a novel teaching model at the university, several first-year students 
struggle with academic performance. Given the varied background and experiences of the adult graduate learners in this course, adult learning theory was also reviewed and considered.

Malcolm Knowles's adult learning theory, andragogy, provided content specific for this population of learners. ${ }^{27}$ The four principles of adult learning theory are 1) offer adult learners the opportunity to be involved in their learning, 2) support adult's internal motivations and acknowledge their prior experiences, 3) make learning relevant to the adult learner, and 4) offer hands-on, realworld problem solving to enhance the learning experience during group activities. ${ }^{28}$ These principles were utilized to theoretically strengthen the conceptual framework applied to the revision of PT 642.

The multimedia principle states that "people learn more deeply from words and pictures than from words alone."29(p.47) However, this does not imply that adding words to pictures is effective. Rather, Mayer's cognitive theory of multimedia learning proposes three main assumptions: 1) that there are two separate channels (auditory and visual) for processing information (Dual-Coding Theory), 2) each channel has a limited capacity, and 3) learning is an active process of filtering, selecting, organizing, and integrating information based upon prior knowledge. ${ }^{30}$ Mayer's cognitive theory of multimedia learning presents the idea that the brain does not interpret a multimedia presentation of words, pictures, and auditory information in a mutually exclusive fashion; rather, these elements are selected and organized dynamically to produce logical mental constructs. Furthermore, Mayer underscores the importance of learning (based upon the testing of content and demonstrating the successful transfer of knowledge) when new information is integrated with prior knowledge. Design principles including providing coherent verbal, pictorial information, guiding the learners to select relevant words and images, and reducing the load for a single processing channel etc. can be gleaned from this theory. ${ }^{30}$ Consideration of the Adult Learning Theory in combination with Mayer's philosophy was foundational to the actual revision of the course format.

There is a paucity of literature pertaining to teaching research methods in PT. A few studies focus on content taught within and across a country, others advocate "learning by doing."11-12 A qualitative study by Hayward described PT student experiences and perceived learning during a Web-enhanced course in research. Four themes addressed issues pertaining to online behavior, communication feature use, students' perceptive of learning, and barriers. Students prefer face to face interaction. Web-enhanced instruction is one available educational strategy that can potentially foster deeper thinking about an assignment and provide opportunities for students to compare their thinking to their peers. ${ }^{13}$ Because some of the original claims of superiority of PBL in developing problem-solving and self-directed learning have not been supported, ${ }^{3}$ other teaching methodologies were considered.

\section{METHODS \\ Revision of PT 642 \\ Flipping the Classroom Concept and Strategy}

The solution to PT 642 was to redesign it utilizing several teaching and learning models simultaneously and move from the traditional teaching model. ${ }^{31}$ The first instructional strategy implemented was to flip the classroom. To bridge the learning gap, an online preparatory module (OPM) was created to increase student success. The asynchronous OPM was created through the university's Learning Management System with the expectation that students learn a portion of the content prior to class. The decision to create an OPM was based on the findings of Botch: a self-paced preparatory course developed to help students prepare for a chemistry course proved successful and suggested that the format could be replicated in other disciplines. ${ }^{32}$ Essentially, this flipped portion of the course prepared students for the direct, synchronous instruction and group activities provided in the traditional classroom setting. In addition to the advantages of a flipped classroom already mentioned, this format also places accountability on the student relieving the instructor of the responsibility to catch students up with basic material. The online self-directed environment inspires the use of technology such as micro learning videos, mobile apps, and self-assessments to create interest and improve the overall quality of the experience; hybrid courses using technology appeal to the adult learner..$^{33}$

De Jong et.al created a problem-based, online learning environment to teach statistics to graduate students enrolled in a public health degree and found that student test results were similar to those taught in a face-to-face synchronous environment. In addition, the online format was suitable for both students and faculty. ${ }^{34}$ Furthermore, the absence of a formal tutor encouraged students to rely on each other in a collaborative and supportive way, indirectly supporting PBL. The PT student cohort is a mix of undergraduates and students from outside of the university, some with stronger backgrounds in EBP than others. The OPMs were intended to help "level the playing field" and bring students with weaker backgrounds forward.

Working with an instructional design specialist, a weekly OPM was created for each content topic using a variety of learning provisions. Each OPM included a reading assignment, Quizlet, micro learning videos, Flipgrid and a Concept Check. The intent of these provisions was to reinforce student learning using a multimedia format. Students were instructed to develop a weekly 
schedule to complete the OPM over the course of several days rather than in one day. The weekly reading assignment reflects the essential reading. Weekly vocabulary lists, extracted from the reading, were added to the syllabus packet. Quizlet is a free mobile and web-based application that allows students to study information via learning tools and games. Students were provided with a link to each module's vocabulary list in Quizlet. They chose how they prefer to interact with the information, learning via auditory and/or visual styles. Quizlet is accessed via mobile app, tablet, and computer. Offering this skill- building study guide with anytime, anywhere capability allows adult students to take control of their prep course learning.

The micro learning videos consist of PowerPoint Presentations with an audio voice-over lecture recorded for each. Information for the micro learning videos directly corresponds with the reading and was chunked and segmented to reduce cognitive load; presenting information within a finite capacity. ${ }^{35}$ Lecture transcripts accompany each PowerPoint Presentation. Flipgrid is another free, online teaching and learning resource; it is a website that allows faculty to create "grids" to facilitate video discussions. Each grid is like a message board where faculty can pose questions and students can post video responses that appear in a tiled grid display.

Concept checks were created using the university's Learning Module System and consisted of short, three to four question quizzes phrased either as multiple choice, true/false, or short answer. Students repeated Concept Checks until mastery. The module was intentionally designed to have repetition and overlap to reinforce key concepts and learning overall. The OPM affords time in-class for activities to facilitate deeper learning and understanding of the content. ${ }^{12,31,26}$ Each class began with a weekly 10-question vocabulary quiz to hold students responsible for the OPM. A short summary lecture and opportunity to ask clarifying content questions followed. Content demanding higher cognitive load was taught during in-class time. Students were then given an inclass assignment to complete either in pairs or small groups. The in-class activities allowed faculty to support learning of the material more directly by guiding students. Class concluded with discussion of the assignment. Many of the in-class assignments were submitted electronically prior to discussion for grading purposes.

\section{Team-Based Learning Concept and Strategy}

Several of the assignments also utilized the TBL format. With this format, pairs of students completed and uploaded an assignment electronically to Blackboard. Students convened with their group and completed the same assignment again and upload to Blackboard. Aligning with PBL, consensus and final answers were derived from student discussion, facilitating a more active learning environment.

\section{Adult Learner Concepts and Strategy}

Much of the course content in the doctoral curriculum is complementary; courses fit well with each other, but PT 642 felt like an "extra" stand-alone course making it difficult for students to prioritize its content. Overcoming learner motivational barriers is essential to the success of PT 642. The significance and impact of the OPM's link to each lesson and each lesson's link back to the OPM is a critical consideration and design feature. Each OPM includes an introduction to the topic, goals, objectives, estimated time to complete tasks, and the plan for in-class time.

To minimize working memory load, information in each OPM is chunked and segmented and micro learning videos delivered focused lessons with only worked examples of statistics being included. To increase working memory capacity with the OPMs, auditory as well as visual information is presented under conditions where both sources of information are essential and supportive to understanding. The OPM caters to a self-paced learning environment that adult learners prefer. In addition, adult learners are goal and relevancy-oriented, therefore short, "aha" moment micro learning videos were created in part to help students relate their prior knowledge to real-life situations. Incorporating relevance through collaborative opportunities via Flipgrid and Concept Checks that included experiential learning also helped tie reality to meaning.

Lastly, to maintain motivation and align learning activities with significance, basic knowledge is tested at the beginning of class, so students' effort with the OPM "counted" toward their final grade. To address student perception of PT 642 as a curriculum outcast, whenever possible, EBP topics were linked to semester tutorial cases. For example, the topic of clinical practice guidelines was taught the same week of the tutorial case with torticollis; the PT 642 class activity had students review and discuss the clinical practice guideline for torticollis. 
Table 1: Assignments and distribution of grading weight

\begin{tabular}{|c|c|c|}
\hline \multicolumn{3}{|c|}{2018 PT 642 EXAMINATIONS AND GRADING POLICY } \\
\hline 1. & Weekly quizzes & $50 \%$ \\
\hline 2. & Evaluation of a research study & $10 \%$ \\
\hline 3. & Homework assignments & $05 \%$ \\
\hline 4. & In-class activities & $10 \%$ \\
\hline 5. & PICO assignment & $25 \%$ \\
\hline \multicolumn{3}{|c|}{2019 PT 642 EXAMINATIONS AND GRADING POLICY } \\
\hline 1. & Weekly quizzes & $15 \%$ \\
\hline 2. & Evaluation of a research study & $10 \%$ \\
\hline 3. & Homework and in-class assignments & $30 \%$ \\
\hline 4. & PICO assignment & $25 \%$ \\
\hline 5. & Weekly online prompts & $05 \%$ \\
\hline 6. & Individual competency quiz & $05 \%$ \\
\hline 7. & Competency quiz group performance & $10 \%$ \\
\hline
\end{tabular}

Because the curriculum design including individual and group work, classroom and homework assignments, assignment weights, quiz questions, and course delivery had substantially changed from 2018 to 2019, it was not possible to conduct a formal research study using these criteria as outcome measures. Rather the results of this project reflect an informal in-class assessment done at the time of midterm. Informal assessment of the OPMs was performed using a "One-Minute Paper" assessment. ${ }^{36}$ Students were given a piece of paper and asked to list "what is helpful" and "what is not helpful" and to refrain from writing their name on the paper. Perceptions about prior knowledge and confidence with EBP as well as class preparation were also gathered informally by the professor through conversations with small groups of students during and outside of class time. This scholarly inquiry qualified for exempt status according to criteria items 6.1.1 and 6.1.4 of the Institutional Review Board at Sacred Heart University; activities reflected normal educational practices and student assessment was de-identified.

\section{RESULTS}

Prior knowledge and familiarity with the content varied amongst the cohort. Some felt unprepared for the course, despite having taken a research course as undergraduates. Others were more confident, having conducted a research project with undergraduate faculty mentorship. Most students were consistently prepared for class as evidenced by their successful performance on their weekly quizzes, class average of 84 . Students reported spending 2-5 hours reviewing each OPM, repeating segments as necessary. This out of class time is comparable to that of year one. The technology savvy students had no issues with the OPMs and appreciated electronic access to course materials. The professor could track completion of Flipgrids and Concept Checks each week. At the beginning of the semester, students completed the OPM over the course of several days as instructed. However, during exam weeks for other courses and towards the end of the semester, the OPMs were more likely to be completed the night before PT 642 class time. Figures 3 and 4 summarizes the tabulated results reported by percentage,of the One Minute Paper assessment about what was helpful and not helpful. It should be noted that the scales of the two tables differ. Students reported that the micro learning videos (PowerPoint with voiceover ( $n=45[71 \%])$, Quizlet $(n=53[84 \%])$, Concept Checks $(n=44[70 \%])$ and the weekly list of vocabulary terms $(n=31(41 \%])$ most helpful, whereas Flipgrids $(n=33[52 \%])$ and reading the textbook $(n=27$ [43\%]) were not helpful. 


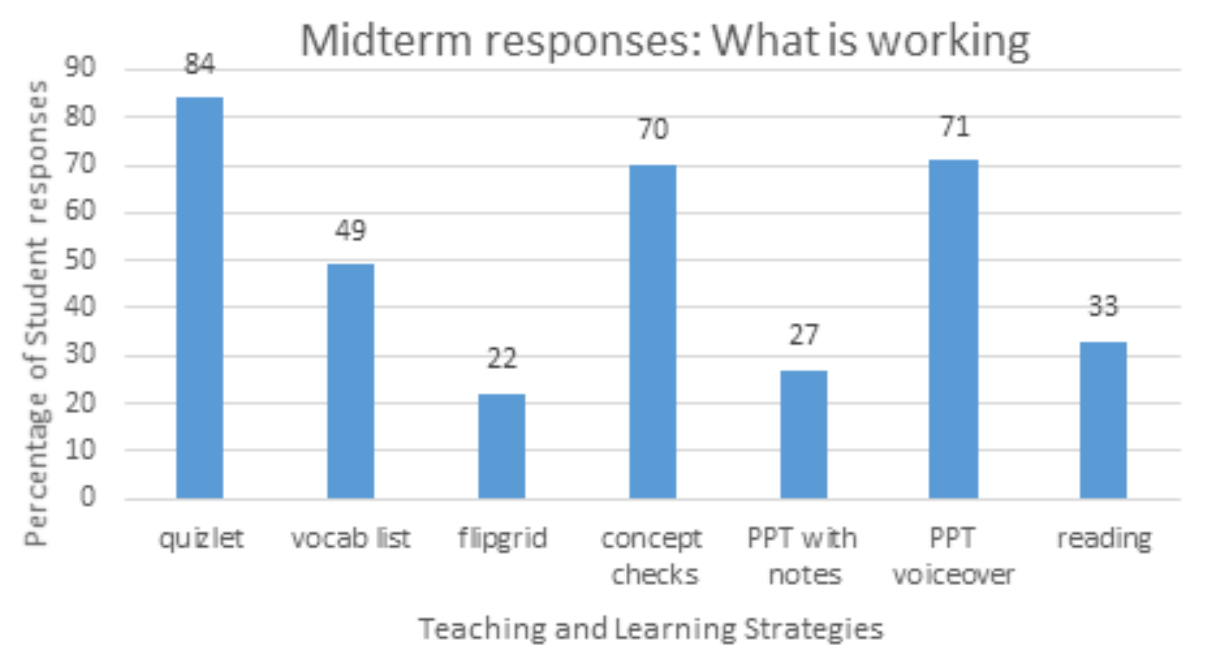

Figure 3. Midterm responses: What is working

$\mathrm{n}=63$

PPT= PowerPoint

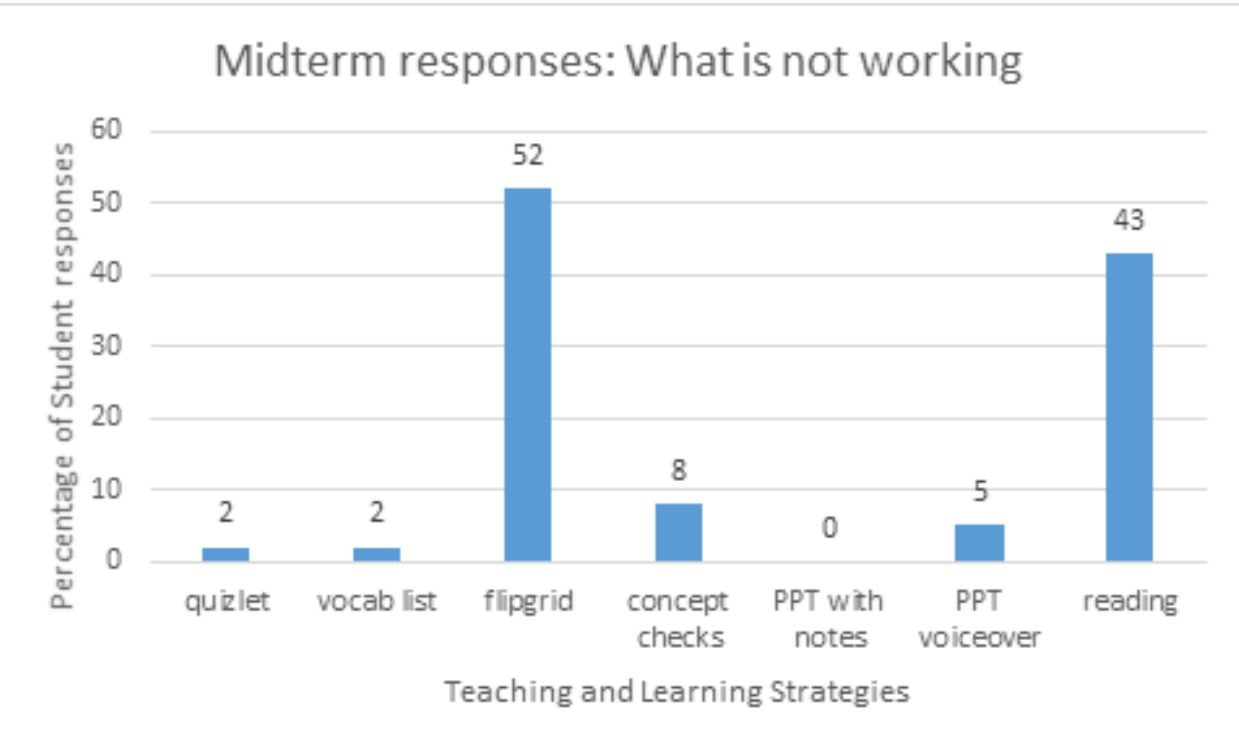

Figure 4. What is not working

$\mathrm{n}=63$

PPT= PowerPoint

\section{DISCUSSION}

The revision of PT 642 resulted in a course that integrated a flipped classroom, team-based learning, and technology in an effort to create a more active learning environment. ${ }^{37}$ Formal assessment of these changes was not possible using student performance as a measure because the course had dramatically changed from year one to year two; the types of assignments and assessments and how they were completed and weighted all differed. Furthermore, the student course evaluation forms also changed from year one to year two, and there was no common question asked of students lending insight relative to the revised course. By the same token, student academic performance year two was similar to year one. 
Limiting the chapter content and list of vocabulary words helped to focus student effort. Providing a technology support, Quizlet, to facilitate learning of terms was appreciated. As to Flipgrid, many of the questions were straightforward, comparing and contrasting two topics or reiterating definitions of the overarching terms. Favorable Flipgrids were those that mandated student opinion. Some students provided additional comments on their One-Minute Papers. Some read the transcript while listening to the PowerPoint with voice-over. Having access to Quizlet via their smartphones provided more opportunity to learn and review the vocabulary words. Repetition and overlap of the content were specifically designed and liked by some, disliked by others. ${ }^{38}$ Initially, some students expressed frustration with this flipped version, stating that learning the material prior to class was challenging. This angst subsided as students became accustomed to the class format and realized that they had opportunity in class to ask questions.

Having been exposed to the content prior to class, some students reported on their One-Minute Papers that they could better understand the summary lecture in class. This exposure also gave them an opportunity to formulate questions to ask in class. Questions led to a deeper conversation about the content, i.e., identifying the strengths and weaknesses of a research design, comparing and contrasting different research designs, limitations of research, discussing what type of study lends well to a particular design, etc. Students also commented on their One-Minute Papers that the in-class activities supported their learning and found the recap discussion of the activity at the end of class most helpful. ${ }^{18}$

The activities in class were designed to foster the higher levels of thinking requiring students to integrate the new material with that previously learned. Having the professor available in the room while students worked through the activity allowed for quick clarification/teaching moments. By linking PT 642 content with the semester content, additional value was added to the course. To develop students as consumers of evidence-based practice, in-class activities often included critical evaluation of research literature. ${ }^{39}$ Essentially, the more demanding cognitive thinking was done in class with faculty support.

The team-based learning activities required that students resolve their conflicts about answers, a facet of experiential learning. ${ }^{37}$ Some stated that their reluctance to engage at the beginning of the semester disappeared when they realized that not speaking resulted in the group's consensus to "go with" the stronger, but wrong answer.

To summarize using Bloom's Taxonomy, the out-of-class OMP addressed knowledge and comprehension, while the in-class activity facilitated application and analysis, and the end of class discussion sometimes aided some students to attain synthesis and evaluation. ${ }^{40}$ This shift enabled a better course balance and promoted higher levels of cognitive learning. From a faculty perspective, the redesign resulted in a course that was much more interesting to teach, as in-class student engagement significantly increased by design. Instead of being "the sage on the stage," faculty was rather "the guide on the side." It was intellectually stimulating to engage in conversation with students rather than "speak at them," and enabled witness to "light bulbs lighting up."

\section{Limitations}

The outcomes provided reflect student perception solely, which may have been biased by the professor's presence in the course, though feedback was both positive and negative. This project lends an educational perspective but lacks scientific rigor.

\section{Recommendations for Future Research}

A more formal, scientific assessment is recommended to determine if and how course changes actually affected student performance. A mixed methods design including a more formal, periodic written assessment of student and faculty perspective is suggested; student focus group discussions would lend depth to the written assessment. The changes made to this once traditionally taught course can be applied to other topics and disciplines.

\section{CONCLUSION}

An evidence-based research course incorporating contemporary teaching methods of flipping the classroom with technology and team-based learning activities resulted in a more positive experience for one class of first-year graduate physical therapy students and their professor. 


\section{References}

1. Commission on Accreditation in Physical Therapy Education. Aggregate Program Data: 2016-2017 Physical Therapy Education Program Fact Sheets. American Physical Therapy Association. www.capteonline.org/uploadedFiles/CAPTEorg/About_CAPTE/Resources/Aggregate_Program_Data/Archived_Aggregate_ Program_Data/2016PTFactSheetFinal.pdf\#search=\%22curriculum\%20models\%202016\%20report\%22 Published 2016. Accessed on May 11, 2020.

2. Barrows HS, Tamblyn RM. Problem-Based Learning: An Approach to Medical Education. New York, New York: Springer Publishing Co; 1980.

3. Saarinen-Rahiika H, Binkley JM. Problem-based learning in physical therapy: a review of the literature and overview of the McMaster University experience. Phys Ther.1998 Feb;78(2):195-207. doi:10.1093/ptj/78.2.195

4. Liceaga AM, Ballard TS, Skura BJ. Incorporating a modified problem-based learning exercise in a traditional lecture and lab-based dairy products course. J Food Sci Educ. 2011 Mar 23;10(2):19-22. doi:10.1111/j.1541-4329.2011.00117.x

5. Lusardi MM, Levangie P, Fein BD. A problem-based learning approach to facilitate evidence-based practice in entry-level health professional education. J Prosthet Orthot; 2002; 14(2): 39-50. http://digitalcommons.sacredheart.edu/pthms_fac

6. Korpi H, Peltokallio L, Piirainen A. problem-based learning in professional studies from the physiotherapy students' perspective. Interdiscip J Probl-Based Learn. 2019 Mar;13(1):1-18. doi:10.7771/1541-5015.1732

7. Morris J. How strong is the case for the adoption of problem-based learning in physiotherapy education in the United Kingdom? Med Teach. 2003 Jul 3;25(1):24. doi:10.1080/0142159021000061387

8. Larin HM, Buccieri KM, Wessel J. Students' perspectives on problem-based learning in a transitional doctorate of physical therapy program. J Scholarsh Teach Learn. 2010;10(3):128-144. https://files.eric.ed.gov/fulltext/EJ906474.pdf

9. Fetters L, Tilson J. Evidence Based Physical Therapy. First edition. Philadelphia, Pennsylvannia: F.A. Davis Company; 2012.

10. Levine D, Tilson JK, Fay D, et al. Evidence-Based Practice Special Interest Group Section on Research Task Force. Doctorate of physical therapy education evidence-based practice curriculum guidelines. 2014. Accessed May 6, 2020. https://aptaeducation.org/pdfs/EBP-PT-ED-MANUAL.pdf?v=001

11. Panhale V, Bellare B, Jiandani $M$. Evidence-based practice in physiotherapy curricula: A survey of Indian health science universities. J Adv Med Educ Prof. 2017 Jul;5(3):101-107. https://pubmed.ncbi.nlm.nih.gov/28761883/.12. Aguado NA. Teaching research methods: Learning by doing. J Public Aff Educ. 2009 Spring;15(2):251-260. doi.org/10.1080/15236803.2009.12001557

13. Hayward LM. Integrating Web-enhanced instruction into a research methods course: Examination of student experiences and perceived learning. J Phys Ther Educ. 2004 Oct;18(2):54-65.

https://journals.Iww.com/jopte/Abstract/2004/07000/Integrating_Web_Enhanced_Instruction_into_a.8.aspx

14. Garrett T. Student-centered and teacher-centered classroom management: A case study of three elementary teachers. 2008;43:14. https://files.eric.ed.gov/fulltext/EJ829018.pdf

15. King A. From sage on the stage to guide on the side. Coll Teach. 1993;41(1):30: 30-35. doi:10.1080/87567555.1993.9926781

16. Nouri J. The flipped classroom: for active, effective and increased learning - especially for low achievers. Intl J Educ Tecnol High Educ. 2016 Aug 24;13(1):33. doi:10.1186/s41239-016-0032-z

17. McLaughlin J, Roth M, Glatt $D$, et al. The flipped classroom: A course redesign to foster learning and engagement in a health professions school. Acad Med. 2014;89(2):236-243. doi:10.1097/ACM.0000000000000086

18. Murray L, McCallum C, Petrosino C. Flipping the classroom experience: A comparison of online learning to traditional lecture. J Phys Ther Educ. 2014;28(3):35-41. doi:10.1097/00001416-201407000-00006

19. Kazanidis I, Pellas N, Fotaris P, Tsinakos A. Can the flipped classroom model improve students' academic performance and training satisfaction in higher education instructional media design courses? Br J Educ Technol. 2019;50(4):2014-2027. doi:10.1111/bjet.12694

20. Jungić $\mathrm{V}$, Kaur H, Mulholland J, Xin C. On flipping the classroom in large first year calculus courses. Int J Math Educ Sci Technol. 2015;46(4):508-520. doi:10.1080/0020739X.2014.990529

21. Konijn WS, Essink DR, de Cock Buning T, Zweekhorst MBM. Flipping the classroom: an effective approach to deal with diversity at higher education. Educ Media Int. 2018;55(1):64-78. doi:10.1080/09523987.2018.1439711

22. Røe Y, Rowe M, Ødegaard NB, Sylliaas H, Dahl-Michelsen T. Learning with technology in physiotherapy education: design, implementation and evaluation of a flipped classroom teaching approach. BMC Med Educ. 2019;19(1):291-291. doi:10.1186/s12909-019-1728-2

23. Michaelsen LK, Sweet M. The essential elements of team-based learning. New Dir Teach Learn. 2008;2008(116):7-27. 4doi:10.1002/tt.330 
24. Jeno LM, Raaheim A, Kristensen SM, et al. The relative effect of team-based learning on motivation and learning: A selfdetermination theory perspective. Eddy SL, ed. CBE-Life Sci Educ. 2017 Winter;16(4):1-12. doi:10.1187/cbe.17-03-0055

25. Macauley K, Dirkes A. Team-based learning at the end of a physical therapy curriculum. J Allied Health Wash. 2017 Nov;46(4):E67-E69. www.ingentaconnect.com/content/asahp/jah

26. Livingston B, Lundy M, Harrington S. Physical therapy students' perceptions of team-based learning in gross anatomy using the Team-Based Learning Student Assessment Instrument. J Educ Eval Health Prof. 2013 Jan;18;11:1-24. doi:10.3352/jeehp.2014.11.1

27. Knowles, Malcolm S. The Adult Learner: A Neglected Species. Houston, Texas: Gulf Publishing Company;1984.

28. Pappas. The Adult Learning Theory - Andragogy - of Malcolm Knowles. eLearning Industry. Published May 9, 2013. Accessed June 8, 2018. https://elearningindustry.com/the-adult-learning-theory-andragogy-of-malcolm-knowles

29. Aliakbari F. The Cognitive Theory of Multimedia Learning. Accessed April 30, 2020. https://www.academia.edu/15062570/The_Cognitive_Theory_of_Multimedia_Learning

30. Mayer RE. Multimedia Learning. Second edition. New York, New York: Cambridge University Press; 2009.

31. Kamwendo K, Törnquist K. Do occupational therapy and physiotherapy students care about research? A survey of perceptions and attitudes to research. Scand J Caring Sci. 2001 Dec 21;15(4):295-302. doi: 10.1046/j.14716712.2001.00041.x

32. Botch B, Day R, Vining W, et al. Effects on student achievement in general chemistry following participation in an online preparatory course. ChemPrep, a voluntary, self-paced, online introduction to chemistry. J Chem Educ. 2007 Mar;84(3):547. doi:10.1021/ed084p547

33. Hughes ES, Bradford J, Likens C. Facilitating collaboration, communication, and critical thinking skills in physical therapy education through technology-enhanced instruction: A case study. TechTrends Link Res Pract Improve Learn. 2018;62(3):296-302. doi:10.1007/s11528-018-0259-8

34. de Jong N, Verstegen DML, Tan FES, O'Connor SJ. A comparison of classroom and online asynchronous problem-based learning for students undertaking statistics training as part of a public health master's degree. Adv Health Sci Educ. 2013 May 18;18(2):245-264. doi:10.1007/s10459-012-9368-x

35. Sweller J. Cognitive load during problem solving: Effects on learning. Cogn Sci. 1988;12(2):257-285. doi:10.1016/03640213(88)90023-7

36. Anderson D, Burns S. One-Minute Paper: Student Perception of Learning Gains. Coll Stud J. 2013 Mar;47(1):219-227. https://eric.ed.gov/?id=EJ1022204

37. Franco MS. Instructional Strategies and Adult Learning Theories: An Autoethnographic Study About Teaching Research Methods in a Doctoral Program. Educ. 2019 Mar 22;(3):178-185. https://www.thefreelibrary.com/INSTRUCTIONAL STRATEGIES AND ADULT LEARNING THEORIES: AN...-a0583693034

38. Bishop J, Verleger M. The flipped classroom: A survey of the research. 120th ASEE Annual Conference \& Exposition. June 23-26, 2013. Atlanta, Georgia Paper \#6219. https://peer.asee.org/2258539. Burger M, Louw QA. Integrating evidencebased principles into the undergraduate physiotherapy research methodology curriculum: Reflections on a new approach. Afri J Health Prof Educ. 2014;6(2):198-201. doi:10.7196/AJHPF.516

40. Bloom, BS. Taxonomy of educational objectives: The classification of educational goals. New York, NY: Longmans Green; 1956. 